\title{
Model for Determining the Competitive Identity of Cities in a Digital Economy
}

\author{
S.N. Lapshina ${ }^{\text {a) }}$, P.S. Murzina ${ }^{\text {b) }}$, A.V. Fedorov ${ }^{\text {() }}$, Thomas Cherny ${ }^{\text {d) }}$ \\ Ural Federal University, Mira 19, Ekaterinburg, Russia, 620002 \\ ${ }^{a}$ Corresponding author: s.n.lapshina@urfu.ru \\ b)p.s.murzina@urfu.ru \\ c)fedorov.urfu@gmail.com \\ d)cerny.tomas@yandex.ru
}

\begin{abstract}
The term competitive identity of cities was introduced by Enholt [1] when considering the notion of territory marketing. Such an indicator is significant for determining the investment attractiveness of the territorial entity, and as a consequence of the opportunities for the development of the Territory and its directions. The assessment and prospects for the development of territories are determined by a set of indicators that are quite stable in time, then it is necessary to determine how to predict the directions for improving the efficiency of investment policy, including in the transition to the digital economy.
\end{abstract}

\section{INTRODUCTION}

Some of consequences of social progress is growth of coherence between various spheres of activity of people, increase in amount of technologies which local application, can have global consequences, and as a result - fast increase in complexity/complexity of the social and economic habitat of the person. In these circumstances, the challenge of computer simulation is to give decision makers as well as socio-economic system researchers effective tools to find solutions. Simulation modeling of existing technologies, business and management systems gives good results in operational and strategic management of the enterprise, production, logistics, supply chains. This is particularly useful in situations with many elements, complex connections and unpredictable developments.

\section{THEORETICAL BACKGROUND AND HYPOTHESES}

The degree of complexity of building a digital economy can vary significantly from industry to industry. The management of territorial development is among the most important areas from which digital transformation should begin. This view is confirmed both by the obvious social significance of the industry and by a number of economic factors. The basis for identifying the development of the Territories is the two main documents, the Territory Master Plan and the Strategic Development Plan. Within the framework of the master plan, transport, architectural and planning, engineering, social, production and environmental aspects of the Territory's development are presented. The town planning regulations establish within the boundaries of the relevant territorial zone the types of permitted use of land plots, as well as everything that is above and below the surface of land plots and is used in the process of their development and subsequent operation of capital construction facilities. Changes in the types of permitted use of land plots are quite rare, taking into account the complexity of this procedure.

The strategic plan reflects the programs of development of territorial education in Fig. 1, the strategic plan of development of Yekaterinburg is presented. 


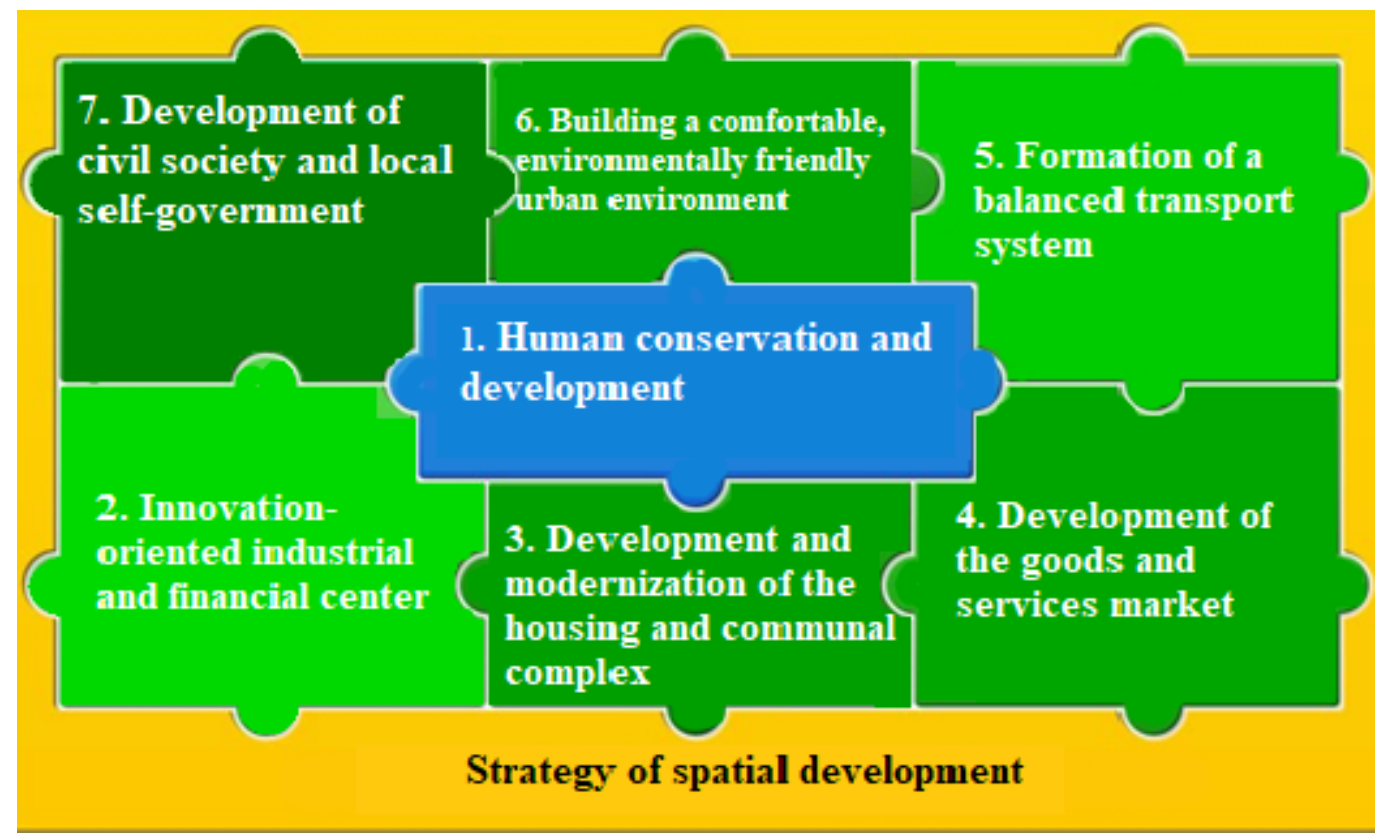

FIGURE 1. Strategic projects by direction [2].

The theme of urban development is on the political agenda. Thus, the President's message to the 2018 Federal Assembly contains theses on the renewal of the urban environment and infrastructure, the deployment of a strategy for the spatial development of Russia and the doubling of expenditures for this purpose. The tools of modernization are stressed separately: "The renewal of the urban environment should be based on the wide introduction of advanced technologies and materials in construction, modern architectural solutions, the use of digital technologies in the work of social facilities, public transport, and public utilities" [2].

Analysis of the literature revealed that both Russian-language and English-language studies after the 1990's rely heavily on the terminology apparatus and methodology outlined by F. Kotler, K. Asplund, I. Rhine, and D. Haider. in their work "Marketing of business". Attracting investments, enterprises and tourists to cities, communes, regions and countries of Europe" is devoted to the practical experience of European territories, and in view of broad citation, it makes sense to identify key theoretical provisions. Five factors determining the marketing results of the functioning of territories in the European space have been identified [3]: the need to achieve superiority in this territory; Conflicting divergence and convergence trends; The Territory's responsibility for marketing and its results; Integration of information technology into marketing; the existence of a communication strategy.

The volume of research on the Territory's marketing is today quite extensive and heterogeneous, due to the interdisciplinary nature of the topic and the significant application component. It is important to emphasize that the subject of territory marketing can be territory of any size and administrative status: macroregion, state, microregion, metropolis, city, village, plot, etc.

The dynamics of development of the Territory is almost very difficult to determine only by considering strategic plans, according to these indicators almost all territorial subdivisions are independent of its transport system, development of the service market, the state of the housing and communal complex, financing. From this point of view, there is little change. And when considering development programs and the dynamics of changes in these documents, it is possible to talk about the dependence of the number of revisions with the rate of development, the more revisions are considered within the framework of the programs, and the more intensive the territorial division develops.

We model the possibilities of determining the competitive identity of the Territory on the basis of the dynamics of changes in territorial programs in certain areas of strategic planning. 


\section{THE METHOD AND THE EMPIRICAL RESULTS}

To determine development prospects, we will use simulation modeling and draw up a model to determine competitive identity for the territorial unit. Such models are widely used in socio-economic studies [4-14].

The basis is a simulation model, with which we will build a trajectory of changes in the state of the system. The rules of development of the system can be set in a variety of ways; in our case will use the dynamics of change of the main parameters, to determine the competitive identity of the territory.

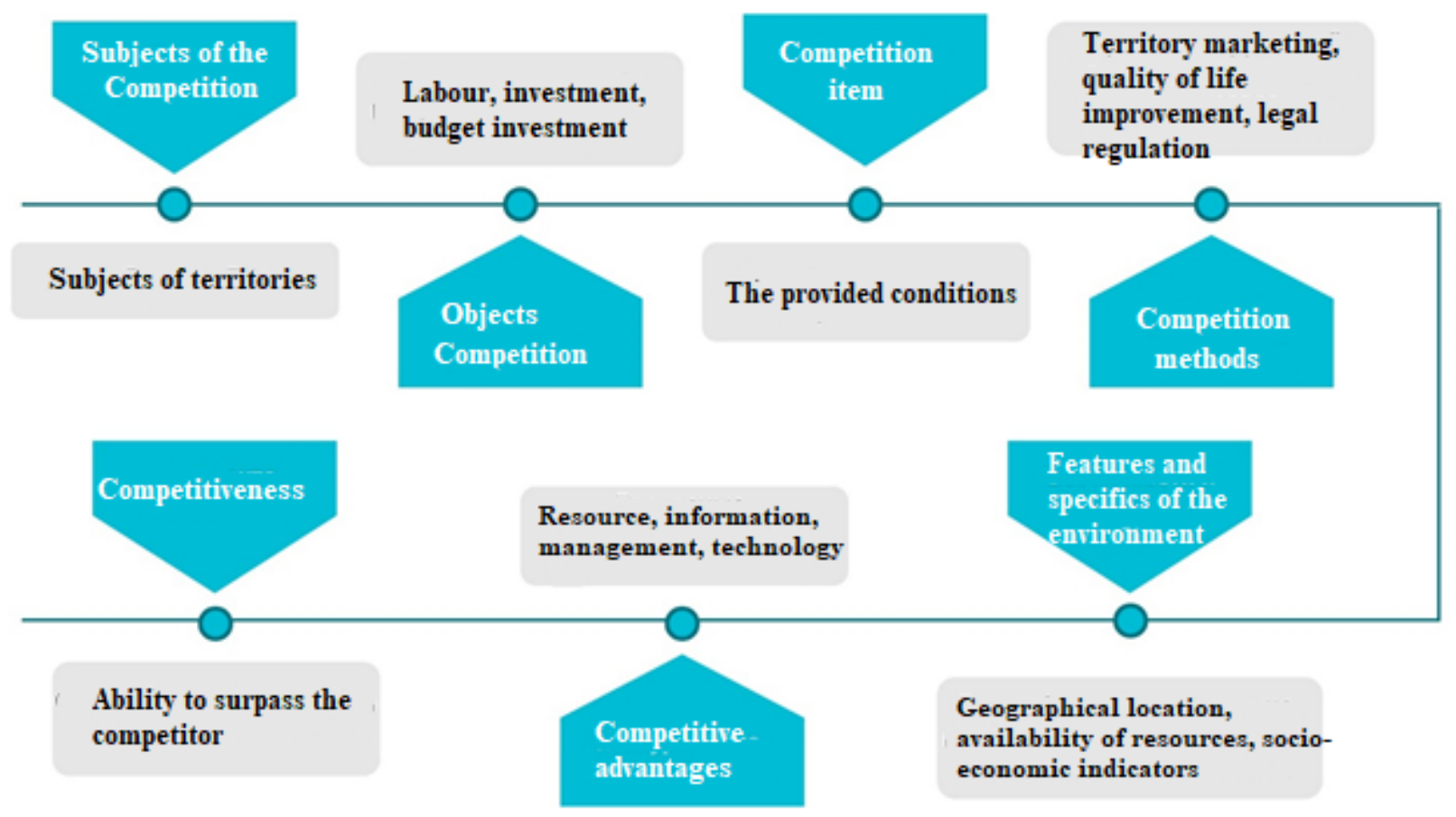

FIGURE 2. Basic Elements for Building a Simulation Model to Determine Competitive Identity

We will base ourselves on the traditional model of the representation of the economic system as an open system, the development of which is based on the interaction of input and output resource flows. If there is an external resource source, the agent inputs the input stream of the resource as an object of competition. From the entire flow, the agent converts as much as its manufacturing capabilities, described by the input and output flows and their ratio, allow. The potential amount of transformation in the simplest case is directly proportional to the assets. As an economic agent, we accept territorial formation, and the source of the resource is the possibility of financial investment from both the State and private investors.

The capabilities of cellular automata [10] as a computational environment allow the evolution of complex dynamic systems with a large number of elements that non-linearly interact with each other. The model, built in the environment of cell machines, allows setting the rules of interaction of agents and patterns of their development. The capabilities of cellular automatics as a computational environment allow the evolution of complex dynamic systems with a large number of elements that non-linearly interact with each other.

Within the framework of the model, it is planned to determine the degree of influence of the main factors affecting the determination of competitive identity of the territorial subdivision by changing the rules for determining the influence on the general function of the main elements highlighted in the model.

\section{CONCLUSION}

The main issue in financing territories from federal and regional budgets, as well as attracting funds of private, including foreign investment resources, the main task is to determine the most promising programs, in terms of 
development of territorial subdivisions. In order to measure the effectiveness of such investments, it is first and foremost necessary to identify the development prospects of the Territory, which are closely linked to the improvement of socio-economic indicators. When selecting the main elements of strategic programs of territory development on the basis of the model of determination of competitive identity, it is possible to form stages of development of road maps on restructuring of the system of management of territorial subdivisions, to identify the most important directions of development in conditions of digitalization and informatization. Identify promising investment projects to improve the competitiveness of territories and, as a result, improve the quality of life of citizens.

\section{REFERENCES}

[1] Anholt S., Competitive Identity: The New Brand Management for Nations, Cities and Regions (New York: Palgrave Macmillan, 2007).

[2] Message from the President of the Russian Federation to the Federal Assembly 01.03.2018, http://www.consultant.ru/document/cons_doc_LAW_99072/9fa2a21b9d67d1f497d57386a6db6c1f6b97f514/.

[3] Kotler F., Asplund K., Rain I., Hyder D., Marketing of places. Attracting investments, enterprises and tourists to cities, communes, regions and European countries (St. Petersburg: Stockholm School of Economics in St. Petersburg, 2005).

[4] O.A. Iskra, E.A. Sizonenko, and Marina Medvedeva, "Imitation model of decision support for mobile applications lifecycle management", AIP Conference Proceedings 1978, 440012 (2018); https://doi.org/10.1063/1.5044041.

[5] Yu.O. Bozhko, T.V. Lavrinenko, M.A. Medvedev, A.M. Gizatulin, and M.Yu. Novikov, "Imitation model for assessment of resource-technological potential of industrial enterprise", AIP Conference Proceedings 2040, 050016 (2018); https://doi.org/10.1063/1.5079114.

[6] Helen A. Iskra, Marina A. Medvedeva, and Anastasiya V. Apanasenko, "An integrated model of efficiency analysis of companies' network interaction", AIP Conference Proceedings 2040, 050019 (2018); https://doi.org/10.1063/1.5079117.

[7] Anna Kolomytseva, Helen Kazakova, Marina Medvedeva, "Interaction Risk Assessment in Partner Entrepreneurial Networks", AIP Conference Proceedings 1978, 440013 (2018); https://doi.org/10.1063/1.5044042.

[8] A.G. Shelomentsev, M.A. Medvedev, D.B. Berg, S.N. Lapshina, A.A. Taubayev, R.H. Davletbaev, and D.V. Savina, "Mathematical model of the competition life cycle under limited resources conditions: problem statement for business community", AIP Conference Proceedings 1910, 020022 (2017); https://doi.org/10.1063/1.5013959.

[9] Anna Kolomytseva, Helen Iskra, Marina Medvedeva and Juliya Glumova, "Imitation modeling of commodity flows in a logistic distribution system", AIP Conference Proceedings 2116, 200030 (2019); https://doi.org/10.1063/1.5114211.

[10] D.B. Berg, K.A. Beklemishev, A.N. Medvedev, M.A. Medvedeva, "Modeling of the competition life cycle using the software complex of cellular automata PyCAlab", AIP Conference Proceedings 1690, 030003 (2015), DOI: $10.1063 / 1.4936702$.

[11] E.A. Iskra, A.N. Medvedev, A.V. Brodskaya and N.A. Medvedev, "On the identification of threats to information security using the method of systemic dynamics", AIP Conference Proceedings 2116, 200026 (2019).

[12] Nikonov O., Medvedeva M., On the Microeconomic Problems Studied by Portfolio Theory, AIP Conference Proceedings, Vol. 1479, 2253-2256 (2012), DOI: 10.1063/1.4756642.

[13] Nikonov O.I., Medvedeva M.A., Efficient Portfolios of the Energy Technologies, AIP Conference Proceedings, Vol. 1389, 565-568 (2011), DOI: 10.1063/1.3636792.

[14] D.A. Tarasov, A.N. Medvedev, A.P. Sergeev, and A.G. Buevich, Review and Possible Development Direction of the Methods for Modeling of Soil Pollutants Spatial Distribution. AIP Conference Proceedings 1863, 050014 (2017). 